\title{
Factors Influencing the Results in Matrix-Associated Autologous Chondrocyte Implantation: A 2 - 5 Year Follow-Up Study
}

\author{
Safa Gursoy ${ }^{\mathrm{a}}$, Mustafa Akkaya ${ }^{\mathrm{a}}$, Mehmet Emin Simsek ${ }^{\mathrm{b}}$, Merve Gursoy ${ }^{\mathrm{c}}$, \\ Metin Dogan ${ }^{\mathrm{a}}$, Murat Bozkurt ${ }^{\mathrm{a}}$
}

\begin{abstract}
Background: This study aimed to investigate the outcomes of matrix-associated autologous chondrocyte implantation (MACI) on the treatment of osteochondral lesions in the knee joint and to determine the factors affecting the functional results.

Methods: The study included 34 patients with a cartilage defect in the knee joint who were applied MACI ${ }^{\circledR}$ (GenzymeBiosurgery, Cambridge, Massachusetts, USA) technique between the years 2010 - 2015. The defect localizations and sizes, past surgeries were recorded. The clinical results were measured with Cincinnati and Lysholm scores.

Results: As a result of the repeated measures at postoperatively, it was found that the patients had increased Lysholm and Cincinnati functional scores in all follow-up periods $(P=0.0001)$. When the mean value of Lysholm and Cincinnati functional scores were assessed according to BMI group, no statistically significant difference was determined $(P=0.941$ and $P=0.779)$. The measurements at 6 and 12 months of the follow-up indicated that the mean scores of the group with no concomitant pathologies were significantly higher than those of the group with concomitant pathologies.
\end{abstract}

Conclusions: The MACI application provides good and stable outcomes for focal cartilage damage in young patients. In order to obtain significant results after autologous chondrocyte implantation, the selection of appropriate patients without concomitant pathologies is required.

Keywords: Knee; Articular cartilage; Matrix-associated autologous chondrocyte implantation; Clinical assessment; Functional scoring

Manuscript submitted December 5, 2018, accepted December 24, 2018

aDepartment of Orthopedics, Ankara Yildirim Beyazit University, Ankara, Turkey

${ }^{\mathrm{b}}$ Ankara Yildirim Beyazit University, Yenimahalle Training and Research Hospital, Ankara, Turkey

'Department of Radiology, Izmir Democracy University, Izmir, Turkey

${ }^{\mathrm{d} C}$ Corresponding Author: Safa Gursoy, Department of Orthopedics and Traumatology, Ankara Yildirim Beyazit University, Ankara 06800, Turkey.

Email: safagursoy@yahoo.com

doi: https://doi.org/10.14740/jocmr3711

\section{Introduction}

Joint cartilage damage is widespread in the general population [1-3]. The healing potential of the cartilage is limited due to its avascular, alymphatic, and neural structure. Many treatment alternatives have been defined and are currently used in the treatment of focal wide cartilage lesions. The most commonly used treatment options such as micro-fracture and mosaicplasty have many disadvantages in respect of functional results in the treatment of cartilage lesions [4-9].

Since the application of autologous chondrocyte implantation (ACI) on the first patient two decades ago, the second and third generation modalities of this treatment have been developed. In matrix-associated autologous chondrocyte implantation (MACI), as the third generation ACI, the autologous chondrocytes to be produced with cell cultures are directly inoculated to scaffolds, which are generally prepared from type I-III collagen via tissue engineering techniques. These cell-scaffold structures to be formed are implanted in the defect area. When compared with other treatments, many studies have indicated the superiority of this technique to other treatment techniques [10-14]. However, no gold standard has been defined as yet for the treatment of focal articular lesions. In order to achieve the desired functional success as a result of the implementation of all these techniques and cell-based treatments, there must be a good understanding of the importance of resolving concomitant pathologies.

The aim of this study was to evaluate the efficacy of MACI in the treatment of osteochondral lesions in the knee joint and to determine the factors affecting the functional results.

\section{Materials and Methods}

This study was approved by the Institutional Review Board (reference number: 26379996/122) of our hospital. A total of 34 patients were applied with the third generation autologous chondrocyte implantation technique by the same surgeon following the approval of the Ministry of Health, Orthopedic Scientific Advisory Committee between 2010 and 2016. In this technique, chondrocytes in the cartilage biopsy taken from the patient's non-weight bearing knee area are isolated by enzymatic digestion and subjected to 2 - 3 passages for 4 weeks in accordance with the in vitro cell culture methods. Approxi- 


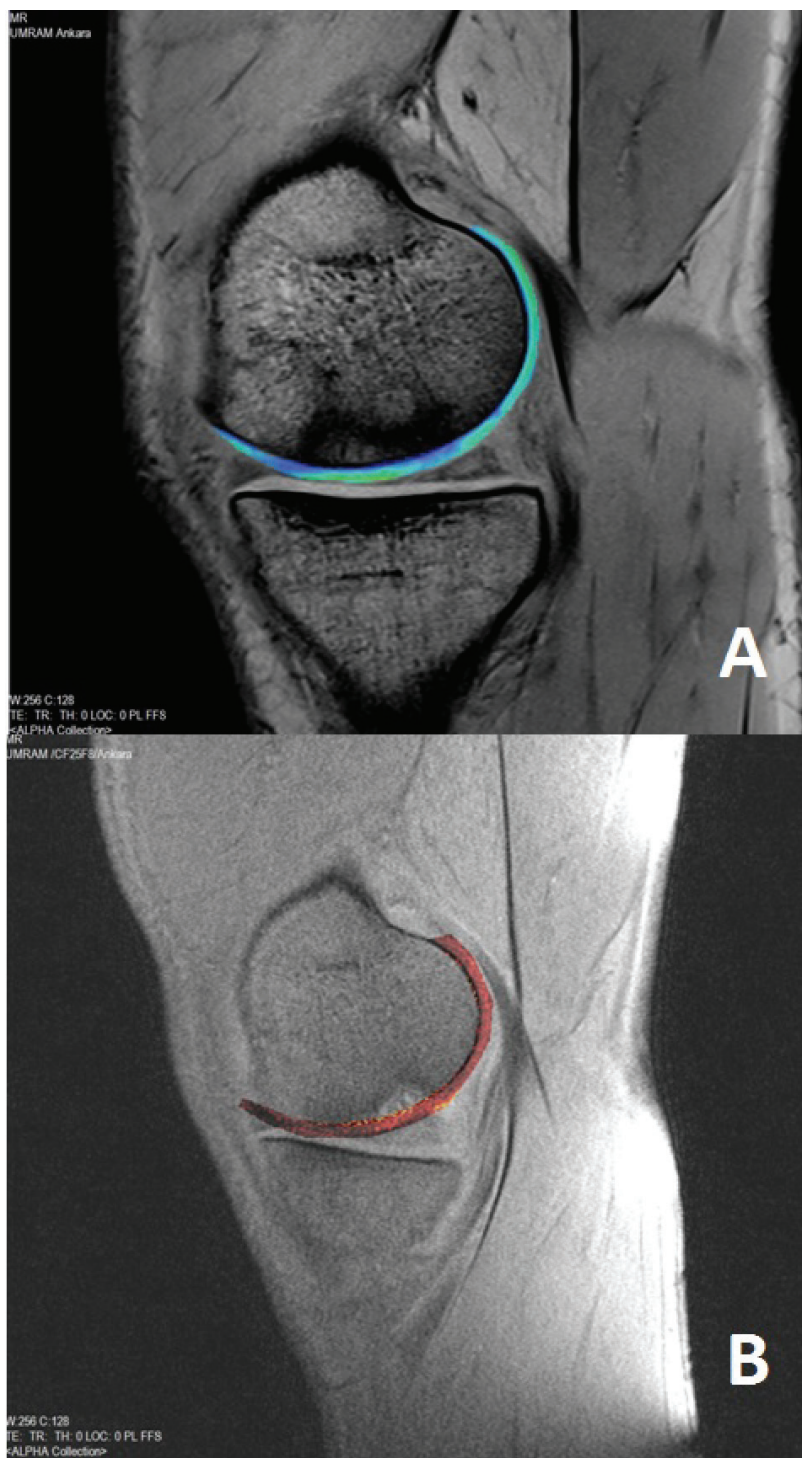

Figure 1. Pre-operative MRI. All patients were evaluated using 3 tesla MRI machine (Trio, Siemens, Erlangen, Germany) and 15-channel transmit-receive birdcage knee coil. Sagittal planes two-dimensional (2D) T1 weighted (W) turbo spin-echo (TSE), 2D T2W gradient-echo (GRE), three-dimensional (3D) proton density W (3D-PDW), 3D short tau inversion recovery (3D-STIR), 3D volume-interpolated breath-hold examination (3D-VIBE), 3D-T2* mapping (A) and postcontrast 3D-T1 dGEMRIC (B) images were obtained. Radiological features of the defect included areas were thicker than native cartilage, rich in water, glycosaminoglycan content decreased and the adjacent bone had an apparent edema on 3T MRI images especially on 3D T1 and T2 mapping images.

mately 14 million cells, which are proliferated by cell culture from 100,000 - 200,000 cells, are inoculated into three-dimensional (3D) biodegradable scaffolds [12].

\section{Surgical technique}

Following clinical and radiological preliminary assessment (Fig. 1), in the first session the lesion was imaged with arthros- copy and a full-thickness cartilage biopsy weighing $200-300$ $\mathrm{mg}$ was taken from around the intercondylar notch in all patients (Fig. 2). In the second session, the MACI ${ }^{\circledR}$ (Genzyme Biosurgery, Cambridge, Massachusetts, USA) implantation that had been obtained from cell culture to collagen type I/ III membranes (Chondro-Gide; Geistlich Biomaterials, Wolhusen, Switzerland) was applied via mini-arthrotomy (Fig. 3).

\section{Patient and treatment characteristics}

The patients comprised 30 males and four females with a mean age of $30.4 \pm 9.3$ years (range, 18 - 48 years). The implantations were performed on the left knee in 22 patients and on the right knee in 12 patients. The defect localization in the knee was determined as medial femoral condyle (MFC) in 24 patients, lateral femoral condyle (LFC) in six patients, MFC and trochlea in two patients and trochlea in two patients. The average body mass index (BMI) of patients was $25.2 \pm 2.6$ $\mathrm{kg} / \mathrm{m}^{2}$, average size of the defect was $5.4 \pm 1.4(3.2-8) \mathrm{cm}^{2}$ and the average length of follow-up was calculated as $22.8 \pm$ 11.1 months. All patients were applied the same surgical procedure as defined above. At the same time, concomitant pathologies were recorded. The demographic data of the patients are presented in Table 1 and the characteristics of the lesions of the patients and the distribution of concomitant pathologies are summarized in Table 2. The study included patients aged 18 - 55 years with focal osteochondral lesions, with lesions larger than $3 \mathrm{~cm}^{2}$ in the knee joint, with normal alignment in the lower extremities, no ligament instability, no meniscus loss more than $50 \%$, and perfect compatibility with the rehabilitation protocol and who attended routine follow-up examinations. Any patients who did not meet these criteria, who had a rheumatologic or systemic disease diagnosis or degenerative changes in the joints were excluded from the study.

\section{Outcome assessment}

All the patients were administered an accelerated rehabilitation program enabling full weight-bearing in the eighth week. The clinical results were measured with Modified Cincinnati, Tegner Lysholm scores in routine polyclinic follow-up examinations, which were recorded preoperatively and at $6,12,24,36$, 48 and 60 months postoperatively. Both scoring systems have been widely used since they were first defined in the early 1980 s [15-17]. The success of these functional scoring systems in assessing many conditions related to knee joint, such as cartilage disorders, ligament damage, meniscus pathologies and patella problems, has been frequently reported in the literature [18, 19].

\section{Statistical method}

The SPSS 17.0 software package was used for the statistical analysis of the data. Categorical values were stated as number and percentage, and continuous variables as mean and standard deviation (median, minimum - maximum when required). For 


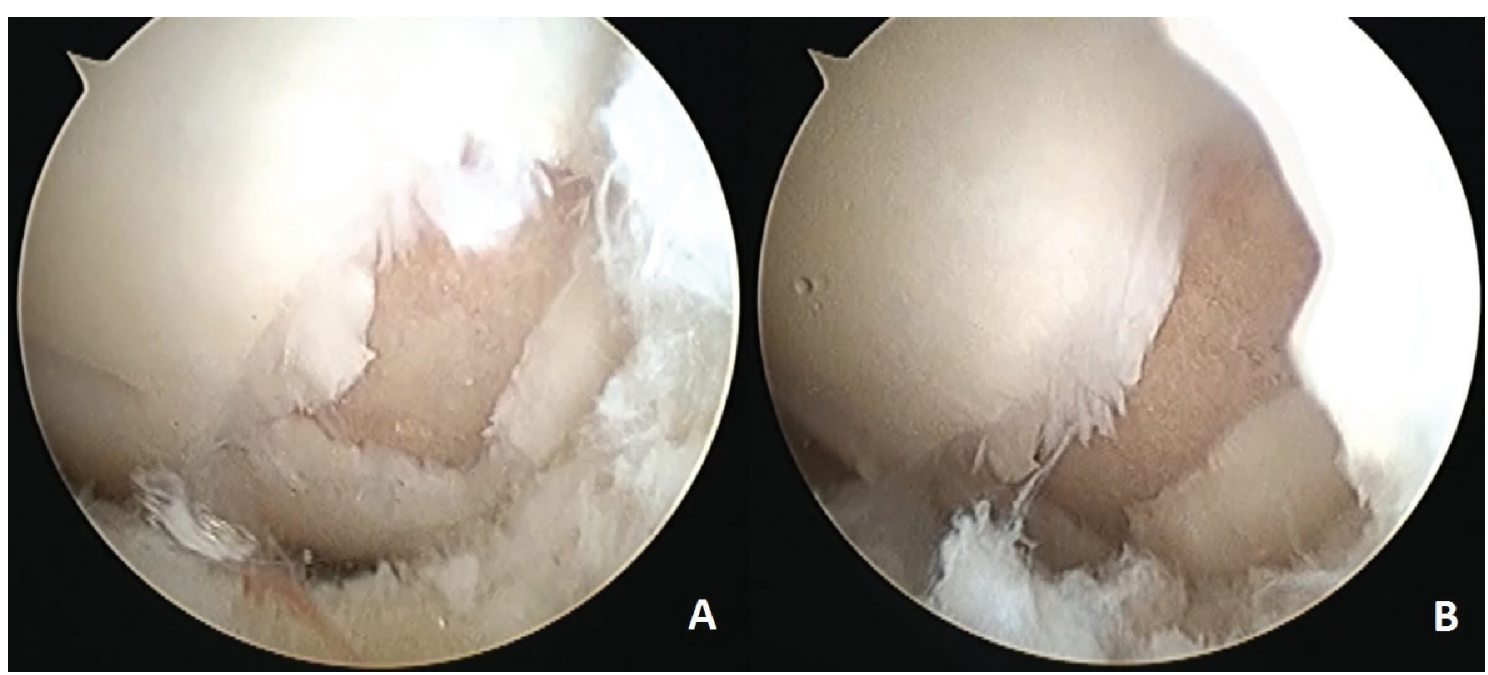

Figure 2. Arthroscopic images. Diagnostic arthroscopy image of the lesion in MFC (A) and indication of the lamination finding at the lesion continuation by the help of the probe (B).

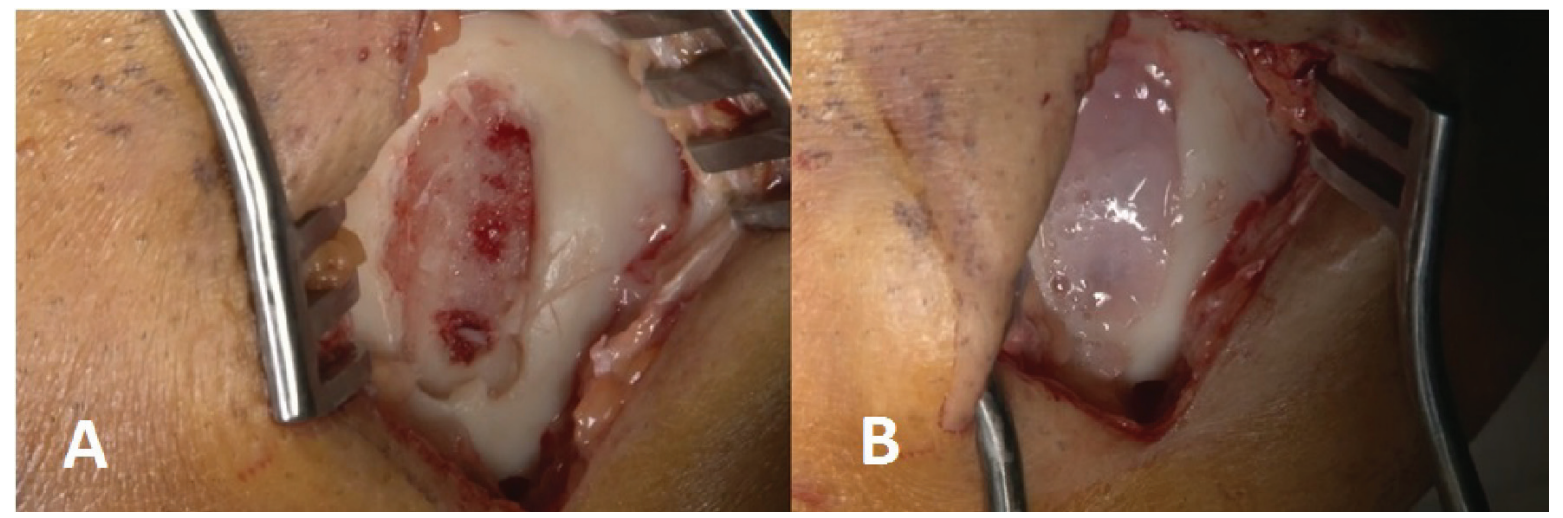

Figure 3. The second session intraoperative images. Image of the lesion in MFC following the debridement (A) and the image after MACI ${ }^{\circ}$ application (B).

the comparison of the measurements among the groups, the Student's $t$-test was used as parametric test conditions were met. For the comparison of repeated measurements, the dependent group $t$-test and repetitive measure variance analysis were used. A value of $\mathrm{P}<0.05$ was accepted as statistically significant in all the tests.

\section{Results}

The changes over time in the Lysholm and Cincinnati func- tional scores are shown in Tables 3 and 4. As a result of the repeated measures postoperatively, statistically significant increase were determined in the Lysholm and Cincinnati functional scores in all follow-up periods $(\mathrm{P}=0.0001$, Table 5$)$.

\section{Distribution of the measures according to gender}

The pre and postoperative follow-up functional scores according to the gender are shown in Tables 6 and 7. While gen-

Table 1. Demographic Distribution of the Data

\begin{tabular}{lllll} 
& Number & Mean \pm SD & Minimum & Maximum \\
\hline Follow up duration (months) & 34 & $22.8 \pm 11.1$ & 10.2 & 56.8 \\
Age $($ year) & 34 & $30.4 \pm 9.3$ & 18 & 48 \\
BMI $\left(\mathrm{kg} / \mathrm{m}^{2}\right)$ & 34 & $25.2 \pm 2.6$ & 20 & 30 \\
Lesion size $\left(\mathrm{cm}^{2}\right)$ & 34 & $5.4 \pm 1.4$ & 3.2 & 8.0 \\
\hline
\end{tabular}

SD: standard deviation; BMI: body mass index. 
Table 2. Demographic Distribution of Data

\begin{tabular}{|lll}
\hline & Number & \% \\
\hline Concomitant pathologies & & \\
\hline Isolated & 19 & 55.9 \\
\hline Anterior cruciate ligament reconstruction & 8 & 23.5 \\
Anterograde drilling & 1 & 2.9 \\
\hline Femoral corrective osteotomy & 1 & 2.9 \\
\hline Meniscal scaffold & 1 & 2.9 \\
\hline Meniscal transplantation & 2 & 5.9 \\
\hline Meniscus repair & 2 & 5.9 \\
\hline Lesion number & & \\
\hline 1 & 31 & 91.2 \\
\hline 2 & 3 & 8.8 \\
Acute/chronic/OCD & & \\
\hline Acute & 3 & 8.8 \\
\hline Chronic & 23 & 67.6 \\
\hline OCD & 8 & 23.5 \\
\hline Traumatic/degenerative & & \\
\hline Degenerative & 10 & 29.4 \\
OCD & 8 & 23.5 \\
\hline Traumatic & 16 & 47.1 \\
\hline
\end{tabular}

OCD: osteochondritis dissecans.

der distributions were examined, no gender comparison was performed since there were only four female patients. In the review of the scale scores of the male patients, the observed increase was seen to be significant.

\section{Distribution of the measures according to BMI}

The patients were grouped as $\mathrm{BMI} \leq 25$ and $\mathrm{BMI}>25$. When the mean value of the Lysholm and Cincinnati functional scores were assessed according to the BMI group variable, no statistically significant difference was determined (Table 8).

\section{Distribution of functional scoring measures according to concomitant pathologies}

Contaminant pathologies were seen in $44.1 \%(n=15)$ of the patients; detailed distribution is given in Table 2. Graphs demonstrating the comparison of average values of Lysholm and Cincinnati scores according to the presence of other pathologies are shown in Figure 4. The measurements at 6 and 12 months indicated that the mean scores of the group with no concomitant pathologies were significantly higher than those of the group with concomitant pathologies. After the 24th month, no statistically significant difference was determined between the scale scores (Tables 9 and 10).

\section{Discussion}

There has been increasing research in the field of bioengineering to provide new technologies and surgical treatment options for the treatment of cartilage lesions. This has led to the use

Table 4. Time Distribution of the Cincinnati Functional Scoring Method

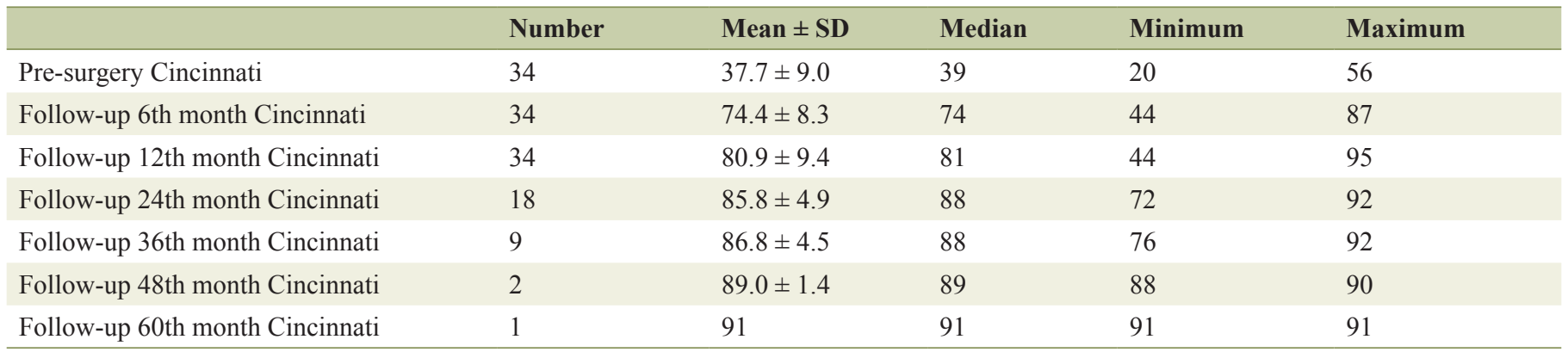

SD: standard deviation.

Table 5. Time Distribution of the Functional Scoring Methods and the Results of the Comparison

\begin{tabular}{|c|c|c|c|c|c|}
\hline & \multirow{2}{*}{ Number } & \multicolumn{2}{|c|}{ Lysholm } & \multicolumn{2}{|c|}{ Cincinnati } \\
\hline & & Mean \pm SD & P value & Mean \pm SD & Pvalue \\
\hline Pre-surgery & 34 & $37.2 \pm 10.1$ & Ref. & $37.7 \pm 9.0$ & Ref. \\
\hline Follow-up 12th month & 34 & $80.6 \pm 8.9$ & 0.0001 & $80.9 \pm 9.4$ & 0.0001 \\
\hline Follow-up 24th month & 18 & $84.9 \pm 4.5$ & 0.0001 & $85.8 \pm 4.9$ & 0.0001 \\
\hline
\end{tabular}

The dependent group $t$-test and repetitive measure variance analysis were used. SD: standard deviation; Ref.: reference. 
Table 6. The Change Distributions of Lysholm Measures According to Time With Reference to Gender

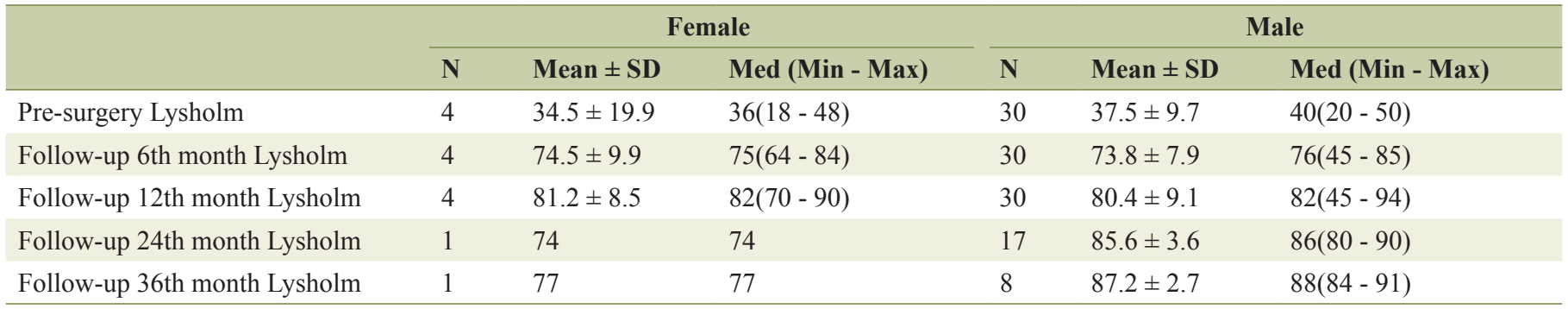

SD: standard deviation; N: number; Med: median; Min: minimum; Max: maximum.

Table 7. The Change Distributions of Cincinnati Measures According to Time With Reference to Gender

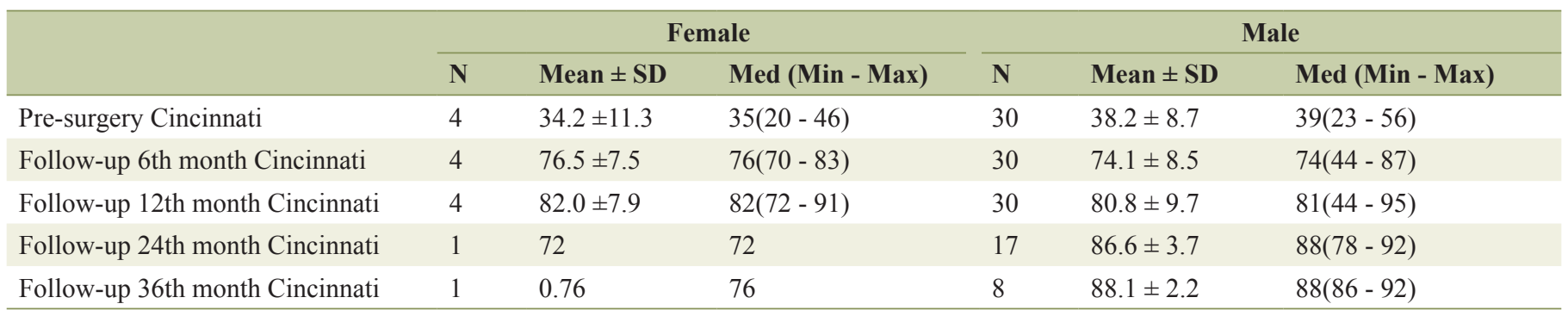

SD: standard deviation; N: number; Med: median; Min: minimum; Max: maximum.

of 3D structures permitting cell growth enabling chondrocyte differentiation [20] and advances following the first generation autologous chondrocyte implantation [21]. The interest in car- tilage regeneration approaches based on scaffold has significantly increased, as can be seen from the increasing number of publications in the literature [22].

Table 8. Result of Comparisons of Lysholm and Cincinnati Measures at Pre- and Post-Operative Distributions With Reference to BMI Groups

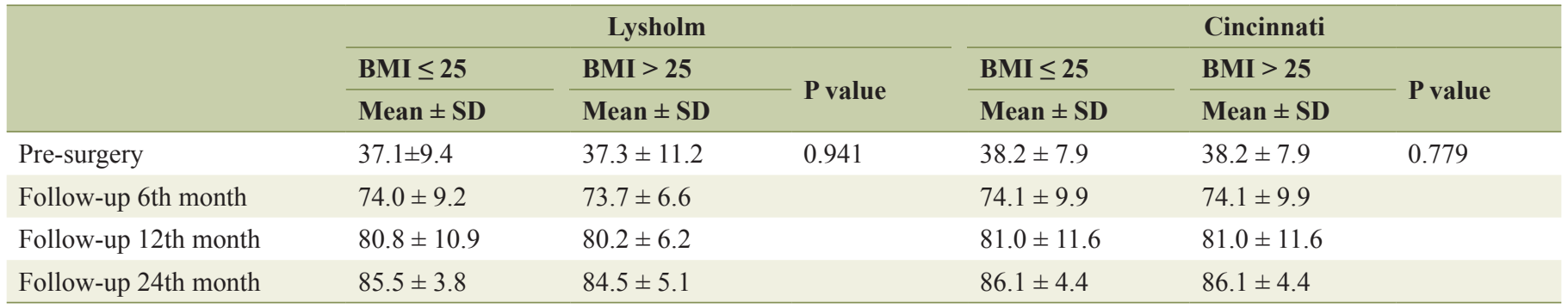

Repetitive measure variance analysis was used. SD: standard deviation; Med: median; Min: minimum; Max: maximum; BMI: body mass index.
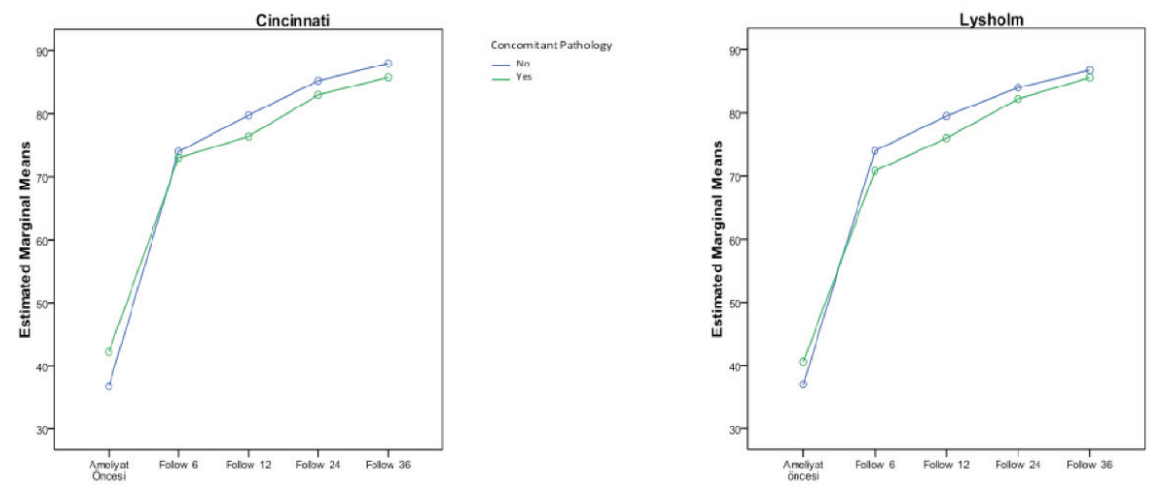

Figure 4. The change graphs of the Lysholm and Cincinnati scoring systems according to the existence of concomitant pathology. 
Table 9. Distribution of Lysholm Measures According to the Existence of Concomitant Pathology

\begin{tabular}{|c|c|c|c|c|c|c|c|}
\hline & \multicolumn{3}{|c|}{ No Pathology $(n=19)$} & \multicolumn{3}{|c|}{ Pathology $(n=15)$} & \multirow{2}{*}{ P value } \\
\hline & $\mathbf{N}$ & Mean \pm SD & Med (Min - Max) & $\mathbf{N}$ & Mean \pm SD & Med (Min - Max) & \\
\hline Pre-surgery Lysholm & 19 & $40.0 \pm 8.7$ & $42(20-50)$ & 15 & $33.4 \pm 11.0$ & $30(18-50)$ & 0.091 \\
\hline Follow-up 12th month Lysholm & 19 & $84.9 \pm 5.2$ & $86(74-94)$ & 15 & $74.6 \pm 9.7$ & $77(45-84)$ & 0.0001 \\
\hline Follow-up 24th month Lysholm & 10 & $86.4 \pm 3.5$ & $87(80-90)$ & 8 & $83.1 \pm 5.1$ & $83(74-90)$ & 0.173 \\
\hline
\end{tabular}

Student's t-test was used. SD: standard deviation; N: number; Med: median; Min: minimum; Max: maximum.

The obtaining of hyaline cartilage is difficult to achieve as the aim of the cartilage restoration [23]. Current treatments are not yet sufficient to achieve this $[24,25]$. The closest results for this aim can be achieved with the hyaline-like cartilage structure as a result of autologous chondrocyte implantation. The experiences of autologous chondrocyte implantation over more than 20 years have provided positive results in terms of clinical and radiological achievements [26].

MACI ${ }^{\circledR}$ is the third generation autologous chondrocyte implantation that was first implemented in 1998 [27]. Although various autologous implantation products that are produced with different bioengineering technologies are applied in our clinic, only the MACI ${ }^{\circledR}$ implementation, which is the largest series, was considered in order not to affect the clinical outcomes of the study and to obtain statistically meaningful results.

There have been many studies in literature researching the clinical outcomes of MACI ${ }^{\circledR}$, which have stated that the technique enables a meaningful increase in the clinical scores of young patients with a focal cartilage lesion $[12,28]$. In addition, successful functional outcomes of autologous chondrocyte implantation with minimally invasive approach in different joints such as hip were also reported in recent studies [29]. Despite the limited number of randomized comparisons in literature, many of these studies are case series. The outcomes of the current study showed significant increases in the modified Cincinnati and Tegner Lysholm clinical results of the patients following the MACI (Table 5). A possible weak aspect of this study researching the efficacy of this relatively new treatment was the relatively low number of cases. In that sense, the level of evidence will be able to be increased with future randomized studies.
As the clinical scoring tests, the modified Cincinnati and Tegner Lysholm scores were used in this study. In literature, other studies have frequently used other scoring techniques such as the IKDC (International Knee Documentation Committee), VAS (Visual Analogue Scale), and WOMAC (Western Ontario and McMaster Universities Arthritis Index) in addition to these two scoring systems. However, there is no consensus as yet as to which system provides the best clinic result assessment of cartilage patients. In recent studies, the limitations of these scoring systems are shown and it is stated that there is a need for improvement [30].

A strong aspect of this study can be said to be the consideration of parameters such as gender, BMI and concomitant pathologies which could affect the result of the treatment to be applied in addition to the changes in clinical scores in general.

Changes in cartilage histology related to gender and the effects of the gender hormones on cartilage health and diseases have been previously indicated in different studies [31]. The receptors for gender hormones, such as 17b-estradiol, progesterone and testosterone in human cartilage have also been demonstrated $[32,33]$. The effect of gender hormones on pathways and pathological processes in cartilage metabolism is also known $[31,34]$. In a study of young patients, more rapid cartilage development was observed in males than females in all joint areas [35]. In adults cartilage volume in males is definitely larger than in females, as has been previously reported [36]. In a 5-year follow-up study of 112 patients by Filardo et al [37], MACI was applied and statistically significant improvements were determined in all patients but at a higher rate in male patients at all follow-up points. The current study included 30 males and four females, and the data to be gained from four female patients were deemed insufficient for

Table 10. Distribution of Cincinnati Measures According to the Existence of Concomitant Pathology

\begin{tabular}{|c|c|c|c|c|c|c|c|}
\hline & \multicolumn{3}{|c|}{ No pathology $(n=19)$} & \multicolumn{3}{|c|}{ Pathology $(n=15)$} & \multirow{2}{*}{ P value } \\
\hline & $\mathbf{N}$ & Mean \pm SD & Med (Min - Max) & $\mathbf{N}$ & Mean \pm SD & Med (Min - Max) & \\
\hline Pre-surgery Cincinnati & 19 & $40.1 \pm 7.3$ & $41(23-50)$ & 15 & $34.5 \pm 10.2$ & $33(20-56)$ & 0.051 \\
\hline Follow-up 12th month Cincinnati & 19 & $85.7 \pm 5.4$ & $87(74-95)$ & 15 & $74.4 \pm 9.9$ & $78(44-85)$ & 0.0001 \\
\hline Follow-up 24th month Cincinnati & 10 & $87.5 \pm 3.5$ & $88(81-92)$ & 8 & $83.8 \pm 6.0$ & $86(72-89)$ & 0.122 \\
\hline
\end{tabular}

SD: standard deviation; N: number; Med: median; Min: minimum; Max: maximum. 
a statistical study. However, when the outcomes were assessed systematically, the scores of the male patients, especially in the 24th and 36th months, were higher than those of the female patients.

Jaiswal et al [38] reported that the clinical outcomes of patients who were applied autologous chondrocyte implantation according to BMI and worse results were observed in overweight or obese patients. In the current study, the patients were grouped as BMI $<25$ and $\mathrm{BMI}>25$ and the outcomes were analyzed. However, there was no significant difference between these two groups. As stated in another study [39] in literature which examined prognostic factors, this can be explained by the homogeneous distribution of the patients and despite overweight patients, there were no obese patients.

Filardo et al compared 62 patients with no surgical history of the knee joints and 71 patients with a surgical history, and although improvements were seen in both groups, statistically worse outcomes were observed in the patients with a history of surgery [39]. In the current study, patients with isolated cartilage lesions were compared with patients with concomitant meniscus pathology, ligament lesion and alignment disorders. The results of the patients with isolated cartilage pathology were observed to be better at all the follow-up examinations and the difference was particularly significant at 6 and 12 months. Krishnan et al [40] found similar results in a study of 199 patients.

It has been claimed that in addition to gender, BMI and concomitant pathologies, some other factors such as age, defect localization, symptom duration of the defect, and affected side, could affect the prognosis of the treatment. There is a need for further studies of larger series to examine the other parameters by forming groups permitting statistical studies.

\section{Conclusions}

The matrix-associated autologous chondrocyte application provides good and stable outcomes in the treatment of focal cartilage injuries in young patients. In order to obtain the desired results after autologous chondrocyte implantation, the selection of appropriate patients and understanding of concomitant pathologies are required.

\section{Conflict of Interest}

The authors declare no conflict of interest.

\section{References}

1. Aroen A, Loken S, Heir S, Alvik E, Ekeland A, Granlund OG, Engebretsen L. Articular cartilage lesions in 993 consecutive knee arthroscopies. Am J Sports Med. 2004;32(1):211-215.

2. Curl WW, Krome J, Gordon ES, Rushing J, Smith BP, Poehling GG. Cartilage injuries: a review of 31,516 knee arthroscopies. Arthroscopy. 1997;13(4):456-460.

3. Widuchowski W, Widuchowski J, Trzaska T. Articular cartilage defects: study of 25,124 knee arthroscopies. Knee. 2007;14(3):177-182.

4. Brittberg M, Lindahl A, Nilsson A, Ohlsson C, Isaksson O, Peterson L. Treatment of deep cartilage defects in the knee with autologous chondrocyte transplantation. N Engl J Med. 1994;331(14):889-895.

5. Hangody L, Fules P. Autologous osteochondral mosaicplasty for the treatment of full-thickness defects of weight-bearing joints: ten years of experimental and clinical experience. J Bone Joint Surg Am. 2003;85-A(Suppl 2):25-32.

6. Iwasaki N, Kato H, Kamishima T, Suenaga N, Minami A. Donor site evaluation after autologous osteochondral mosaicplasty for cartilaginous lesions of the elbow joint. Am J Sports Med. 2007;35(12):2096-2100.

7. Petersen EF, Fishbein KW, Laouar L, Spencer RG, Wenz JF. Ex vivo magnetic resonance microscopy of an osteochondral transfer. J Magn Reson Imaging. 2003;17(5):603-608.

8. Reddy S, Pedowitz DI, Parekh SG, Sennett BJ, Okereke E. The morbidity associated with osteochondral harvest from asymptomatic knees for the treatment of osteochondral lesions of the talus. Am J Sports Med. 2007;35(1):8085.

9. Steadman JR, Briggs KK, Rodrigo JJ, Kocher MS, Gill TJ, Rodkey WG. Outcomes of microfracture for traumatic chondral defects of the knee: average 11-year followup. Arthroscopy. 2003;19(5):477-484.

10. Bachmann G, Basad E, Lommel D, Steinmeyer J. [MRI in the follow-up of matrix-supported autologous chondrocyte transplantation (MACI) and microfracture]. Radiologe. 2004;44(8):773-782.

11. Bartlett W, Skinner JA, Gooding CR, Carrington RW, Flanagan AM, Briggs TW, Bentley G. Autologous chondrocyte implantation versus matrix-induced autologous chondrocyte implantation for osteochondral defects of the knee: a prospective, randomised study. J Bone Joint Surg Br. 2005;87(5):640-645.

12. Behrens P, Bitter T, Kurz B, Russlies M. Matrix-associated autologous chondrocyte transplantation/implantation (MACT/MACI) - 5-year follow-up. Knee. 2006;13(3):194-202.

13. Cherubino P, Grassi FA, Bulgheroni P, Ronga M. Autologous chondrocyte implantation using a bilayer collagen membrane: a preliminary report. J Orthop Surg (Hong Kong). 2003;11(1):10-15.

14. D'Anchise R, Manta N, Prospero E, Bevilacqua C, Gigante A. Autologous implantation of chondrocytes on a solid collagen scaffold:clinical and histological outcomes after two years of follow-up. J Orthop Traumatol. 2005;6:36-43.

15. Noyes FR, Matthews DS, Mooar PA, Grood ES. The symptomatic anterior cruciate-deficient knee. Part II: the results of rehabilitation, activity modification, and counseling on functional disability. J Bone Joint Surg Am. 1983;65(2):163-174.

16. Noyes FR, Mooar PA, Matthews DS, Butler DL. The symptomatic anterior cruciate-deficient knee. Part I: the long-term functional disability in athletically active indi- 
viduals. J Bone Joint Surg Am. 1983;65(2):154-162.

17. Lysholm J, Gillquist J. Evaluation of knee ligament surgery results with special emphasis on use of a scoring scale. Am J Sports Med. 1982;10(3):150-154.

18. Briggs KK, Kocher MS, Rodkey WG, Steadman JR. Reliability, validity, and responsiveness of the Lysholm knee score and Tegner activity scale for patients with meniscal injury of the knee. J Bone Joint Surg Am. 2006;88(4):698705.

19. Paxton EW, Fithian DC, Stone ML, Silva P. The reliability and validity of knee-specific and general health instruments in assessing acute patellar dislocation outcomes. Am J Sports Med. 2003;31(4):487-492.

20. Grigolo B, Lisignoli G, Piacentini A, Fiorini M, Gobbi P, Mazzotti G, Duca M, et al. Evidence for redifferentiation of human chondrocytes grown on a hyaluronanbased biomaterial (HYAff 11): molecular, immunohistochemical and ultrastructural analysis. Biomaterials. 2002;23(4):1187-1195.

21. Sharma B, Elisseeff JH. Engineering structurally organized cartilage and bone tissues. Ann Biomed Eng. 2004;32(1):148-159.

22. Kon E, Filardo G, Di Matteo B, Perdisa F, Marcacci M. Matrix assisted autologous chondrocyte transplantation for cartilage treatment: A systematic review. Bone Joint Res. 2013;2(2):18-25.

23. Anderson AF, Irrgang JJ, Kocher MS, Mann BJ, Harrast JJ, International Knee Documentation $\mathrm{C}$. The international knee documentation committee subjective knee evaluation form: normative data. Am J Sports Med. 2006;34(1):128-135.

24. Gobbi A, Bathan L. Biological approaches for cartilage repair. J Knee Surg. 2009;22(1):36-44.

25. Gomoll AH, Filardo G, de Girolamo L, EspregueiraMendes J, Marcacci M, Rodkey WG, Steadman JR, et al. Surgical treatment for early osteoarthritis. Part I: cartilage repair procedures. Knee Surg Sports Traumatol Arthrosc. 2012;20(3):450-466.

26. Vasiliadis HS, Danielson B, Ljungberg M, McKeon B, Lindahl A, Peterson L. Autologous chondrocyte implantation in cartilage lesions of the knee: long-term evaluation with magnetic resonance imaging and delayed gadolinium-enhanced magnetic resonance imaging technique. Am J Sports Med. 2010;38(5):943-949.

27. Behrens P, Ehlers EM, Kochermann KU, Rohwedel J, Russlies M, Plotz W. [New therapy procedure for localized cartilage defects. Encouraging results with autologous chondrocyte implantation]. MMW Fortschr Med. 1999; 141(45):49-51.

28. Gille J, Behrens P, Schulz AP, Oheim R, Kienast B. Matrix-associated autologous chondrocyte implantation: a clinical follow-up at 15 years. Cartilage. 2016;7(4):309315 .

29. Krueger DR, Gesslein M, Schuetz M, Perka C, Schroed- er JH. Injectable autologous chondrocyte implantation (ACI) in acetabular cartilage defects - three-year results, Journal of Hip Preservation Surgery. 2018.

30. RP EA, Giordano V, Calixto A, Malzac F, Aguiar C, do Amaral NP, Carvalho AC. Analysis on the modified lysholm functional protocol among patients with normal knees. Rev Bras Ortop. 2011;46(6):668-674.

31. Claassen H, Schicht M, Paulsen F. Impact of sex hormones, insulin, growth factors and peptides on cartilage health and disease. Prog Histochem Cytochem. 2011;45(4):239-293.

32. Ben-Hur H, Thole HH, Mashiah A, Insler V, Berman V, Shezen E, Elias D, et al. Estrogen, progesterone and testosterone receptors in human fetal cartilaginous tissue: immunohistochemical studies. Calcif Tissue Int. 1997;60(6):520-526.

33. Claassen H, Schicht M, Brandt J, Reuse K, Schadlich R, Goldring MB, Guddat SS, et al. C-28/I2 and T/C-28a2 chondrocytes as well as human primary articular chondrocytes express sex hormone and insulin receptors Useful cells in study of cartilage metabolism. Ann Anat. 2011;193(1):23-29.

34. Guerne PA, Carson DA, Lotz M. IL-6 production by human articular chondrocytes. Modulation of its synthesis by cytokines, growth factors, and hormones in vitro. J Immunol. 1990;144(2):499-505.

35. Jones G, Ding C, Glisson M, Hynes K, Ma D, Cicuttini F. Knee articular cartilage development in children: a longitudinal study of the effect of sex, growth, body composition, and physical activity. Pediatr Res. 2003;54(2):230236.

36. Cicuttini F, Forbes A, Morris K, Darling S, Bailey M, Stuckey S. Gender differences in knee cartilage volume as measured by magnetic resonance imaging. Osteoarthritis Cartilage. 1999;7(3):265-271.

37. Filardo G, Kon E, Andriolo L, Vannini F, Buda R, Ferruzzi A, Giannini S, et al. Does patient sex influence cartilage surgery outcome? Analysis of results at 5-year follow-up in a large cohort of patients treated with Matrix-assisted autologous chondrocyte transplantation. Am J Sports Med. 2013;41(8):1827-1834.

38. Jaiswal PK, Bentley G, Carrington RW, Skinner JA, Briggs TW. The adverse effect of elevated body mass index on outcome after autologous chondrocyte implantation. J Bone Joint Surg Br. 2012;94(10):1377-1381.

39. Filardo G, Kon E, Andriolo L, Di Matteo B, Balboni F, Marcacci M. Clinical profiling in cartilage regeneration: prognostic factors for midterm results of matrix-assisted autologous chondrocyte transplantation. Am J Sports Med. 2014;42(4):898-905.

40. Krishnan SP, Skinner JA, Bartlett W, Carrington RW, Flanagan AM, Briggs TW, Bentley G. Who is the ideal candidate for autologous chondrocyte implantation? J Bone Joint Surg Br. 2006;88(1):61-64. 